\title{
Correction to: A comparison of five methods in landslide susceptibility assessment: a case study from the 330-kV transmission line in Gansu Region, China
}

\author{
Yunfeng Ge ${ }^{1} \cdot$ Hongzhi Chen ${ }^{1} \cdot$ Binbin Zhao ${ }^{2} \cdot$ Huiming Tang ${ }^{1} \cdot$ Zishan Lin $^{1} \cdot$ Zhiguo Xie $^{1} \cdot$ Le Lv $^{1} \cdot$ Peng Zhong ${ }^{1}$ \\ Published online: 13 October 2018 \\ ๑) Springer-Verlag GmbH Germany, part of Springer Nature 2018
}

Correction to: Environmental Earth Sciences (2018) 77:662

https://doi.org/10.1007/s12665-018-7814-7

In the original publication, the author name Bingbing Zhao was published incorrectly. The correct name should be Binbin Zhao.

The original article has been corrected.

The original article can be found online at https://doi.org/10.1007/ s12665-018-7814-7.

Huiming Tang

tanghm@cug.edu.cn

1 Faculty of Engineering, China University of Geosciences,

Wuhan, Hubei, China

2 Research Institute of Transmission and Transformation

Projects, China Electric Power Research Institute Co., Ltd,

State Grid Corporation of China, Beijing, China 